January 1986. Weather, 42, pp. 29-30

(1990a) Temperature profiles at Binbrook on 2

February 1986. Weather, 45, pp. 32-33

- (1990b) Snowfall of 3 February 1990. Weather, 45, p. 385

(1991) More on snowfalls resulting from lower-

ing of the freezing level. Weather, 46, p. 61

- (1998) The snowfall of 19 November 1996.

Weather, 53, p. 29
Meade, P. J. (1986) Transatlantic civil aviation - the initial phase: the first training course for scientists in the Meteorological Office. Meteorol. Mag., 155, pp. 193-199

Correspondence to: $\mathrm{Mr}$ W. S. Pike, 19 Inholmes Common, Woodlands St. Mary, Hungerford, Berkshire RG17 7SX.

\title{
Weather and horse racing: Towards a more objective prediction of the going
}

\author{
Marie Sheridan and John Sweeney \\ Department of Geography, National University of Ireland
}

The 'going' at a race meeting, that is the condition of the ground, is as much a part of horse racing as are the horse and jockey taking part in the race. The going, determined principally by antecedent weather conditions, is such an important consideration that it can explain the difference between a horse winning and losing a, perhaps very lucrative, race. At present, the clerk of the course declares the condition of the ground on the morning of a meeting. This can be too late for many owners and trainers, since the ground may not suit their horses - leading them to be withdrawn and the owner highly penalised. During warm summers in Britain, for example in 1995 and 1996, extra firm ground resulted in the depletion of entrants at several race meetings. In contrast, a trainer may find on other occasions that the going is unexpectedly favourable and would be willing to pay a late entry fee for a race. With an ability to forecast, with some degree of confidence, what the going will be, even a day or two before a meeting, a trainer might improve his/ her chances of selecting appropriate 'horses for courses' as well as minimising unnecessary financial outlays for the stable and owner concerned.

In a wider context, currently there is an expectation that increases in winter rainfall and decreases in summer rainfall will occur in association with the enhanced greenhouse effect
(Hulme and Barrow 1997). Such changes would further increase the likelihood of adverse going in both these seasons and render forecasts of the going even more valuable than they are at present.

\section{The going}

The going refers to the state of the ground on the racecourse and is categorised on a scale from 'heavy' to 'firm'. Heavy conditions are experienced when the soil is almost fully saturated from rainfall, with downward percolation from the surface having effectively ceased. Firm ground, on the other hand, refers to dry ground with a soil moisture deficit existing at the surface, most commonly experienced at summer race meetings. Soil moisture deficits occur principally as a result of evapotranspiration losses from the layers of soil close to the surface which in the British Isles may average approximately $3 \mathrm{~mm}$ day $^{-1}$ during the summer months (Keane 1986). The intervening conditions between these extremes go in order from heavy, soft to heavy, soft, yielding to soft, yielding, good to yielding, good, good to firm and firm. The ideal condition for racing is good the slightly wetted soil provides a perfect surface to run on and suits the natural leg action of the horse as it strides over the terrain. Indeed, one calibration of the going is provided 
by the depth to which a horse's hooves would penetrate the surface. With soft ground, for example, the horse's hooves would sink 10$15 \mathrm{~cm}$ into the soil, while with firm ground the hoof would barely break the surface structure (Fortune, personal communication).

The importance of the condition of the ground to a horse's racing performance cannot be overestimated. The expression "the horse did not go on the ground" is a common phrase implying that the horse did not run to its full potential on the going prevailing on the day. The causes of these differences in performance are related to the pedigree and leg action of particular horses, and are beyond the scope of this study. But clearly there is a huge economic importance in the going for jockeys, owners, trainers, punters, and any individual with a vested interest in horse racing.

Measurement of the going is currently a very subjective process. It involves the clerk of the course making a decision on how deep a stick penetrates into the ground. Prior to any race meeting, the clerk of the course walks the track and at intervals penetrates the ground with a stick. Judging how easily, freely and deeply the stick goes down through the soil determines what the going will be declared as. Unfortunately from a consistency point of view, the clerk of the course is not the same person at each racetrack. However, in Ireland at least, one official common to all racetracks is the inspector of racecourses. This individual walks every racetrack in Ireland the day before a meeting. Although the clerk makes the final determination of the going, frequently some discussion may take place with the inspector in reaching this decision. The arrangement also provides some degree of consistency over time as new clerks and new inspectors take up their jobs. No particular qualification for either job is necessary. Usually the appointments are made on the basis of experience and accumulated expertise in the racing industry. Once determined, the going is announced on the morning of the meeting for trainers, owners, and public.

The above approach reflects the practical difficulties of measuring soil water content at a large number of points quickly and accurately. The standard thermogravimetric method is to take a soil sample of known volume and record the weight loss consequent on drying it in an oven. This is obviously both destructive and time-consuming and is not feasible for the clerk of the course to undertake. Alternative, indirect, methods such as capacitance probes have been found to provide a high correlation with the standard gravimetric method (Robinson and Dean 1993); these have now been employed on some English racecourses and in some ways represent a technological enhancement of the clerk of the course's stick.

\section{Management of soil conditions at racecourses \\ Compaction}

The major problem faced in managing a racecourse is the effect of soil compaction. Depending on the level of usage, horses' hooves can apply very high pressures which can alter soil structure and texture. The water content is crucial in determining susceptibility to compaction. As the moisture content of a soil increases, its shear strength diminishes and its deformation under stress characteristics alters (Morgan 1985). When wetted, soil structure can be adversely affected by compression as a result of the deflocculation of clays (Russell 1973). Dry soil on the other hand cracks more readily, allowing particles to disaggregate. This inhibits compaction.

Compaction causes the solid particles in the soil to slide over one another, reducing pore size and impeding drainage. Since pore size is also an important consideration for the circulation of air, an essential determinant of fertility and grass growth, excessive compaction is an unwelcome occurrence at a racetrack. Similarly, since plant roots tend to follow lines of least resistance, such as pores, cracks or old root channels, compaction will tend to close these avenues and inhibit root development, thus reducing grass growth (Culleton 1999).

Measurements of horses' hooves show that they are approximately circular with a diameter of $15 \mathrm{~cm}$. On average, thoroughbreds weigh about $550 \mathrm{~kg}$, meaning that their static load is about $80 \mathrm{kPa}$ (0.8 atmospheres). For comparison, an adult man exerts a static load of about $17 \mathrm{kPa}$ (Mulqueen, personal communication). 
The exact impact that the horse has on the ground depends on whether it is walking or galloping, and the state of the ground itself. The maximum force of a galloping hoof on hard ground is about $10 \mathrm{kN}$. ${ }^{\star}$ With up to 28 horses taking part in a race, and on average seven races per day during a meeting, the cumulative effect on the soil is considerable. On softer ground, deformation of the soil may extend below the top $20 \mathrm{~cm}$ and the track becomes much more susceptible to waterlogging. Once surface water appears in any quantity on a track, there is a strong risk that the meeting will be abandoned.

Preventing compaction can be achieved by filling holes left from the imprint of hooves after racing. This will protect the lower layers in the soil, particularly if sand is used. Natural rejuvenation is perhaps the best solution, however, whereby leaving the racecourse untouched, especially during the summer, allows dry soil to crack and soil particles to loosen up. Limited use of a tractor, and even then one with increased tyre size, also helps.

\section{Grass growth}

A good grass growth protects the soil from the impact of raindrops and also affords a modicum of protection for the topsoil from the pressure exerted by hooves. Raindrops falling directly on to bare soil can damage the 'crumb structure' of soil and lead to surface sealing and erosion. Vigorous grass growth is promoted by an active root system that provides cohesion for the soil. A grass cover can also act as a springy surface on which the horses run, thus protecting their legs as well as protecting the topsoil. The best known thoroughbred rearing and training area in the British Isles is the Curragh of Co. Kildare, a fluvioglacial outwash plain or sandur, where the free-draining sand and gravel subsoil encourages short, springy grass and an open, treeless, landscape ideal for training horses safely.

\section{Watering}

Racetrack managers seldom have control over the condition of the ground and are dependent on weather conditions to determine the going.
In warm, dry weather, however, the racecourse can become so hard that it would be dangerous for horses. Watering the track in this case can bring the going back to firm, good to firm or even good, thus allowing the meeting to proceed. Tracks are generally watered using a sprinkler system or from a tractor-towed tank. Many trainers disagree with watering since the state of the ground can be altered to ensure a specific type of going, such as good, instead of another, such as firm. The procedure may thus favour some horses over others and the issues become as much ethical as safety-related. Although weather forecasts have achieved considerable improvements in reliability in recent years (today's 72-hour forecasts are similar in accuracy to their 24-hour counterparts in the early 1970s) there is always a risk that, after watering, rain that has not been forecast may create unduly soft conditions. This can expose the manager and clerk of the course to criticism for its condition. However, watering is generally used to change the ground from a situation where racing would not be permitted to one whereby the meeting could be salvaged.

\section{The courses studied}

Five Irish racetracks were selected for study. Each has all-year-round racing incorporating both flat and national hunt events. The courses were representative of a range of subsoil conditions as well as management practices. They were also relatively close to synoptic meteorological stations from which representative weather data were obtained (Fig. 1).

\section{Punchestown}

The Punchestown track, located in Co. Kildare close to the town of Naas, is under $4 \mathrm{~km}$ round and hosts 11 meetings per year. No meetings are generally held in the summer, allowing the track to recover. The soil base is predominantly of fluvioglacial sands and gravels, a loamy soil which allows good drainage. Even in the wettest winters the track may remain raceable.

\footnotetext{
* Similar to allowing a container with 1000 litres of water to fall to the ground.
} 


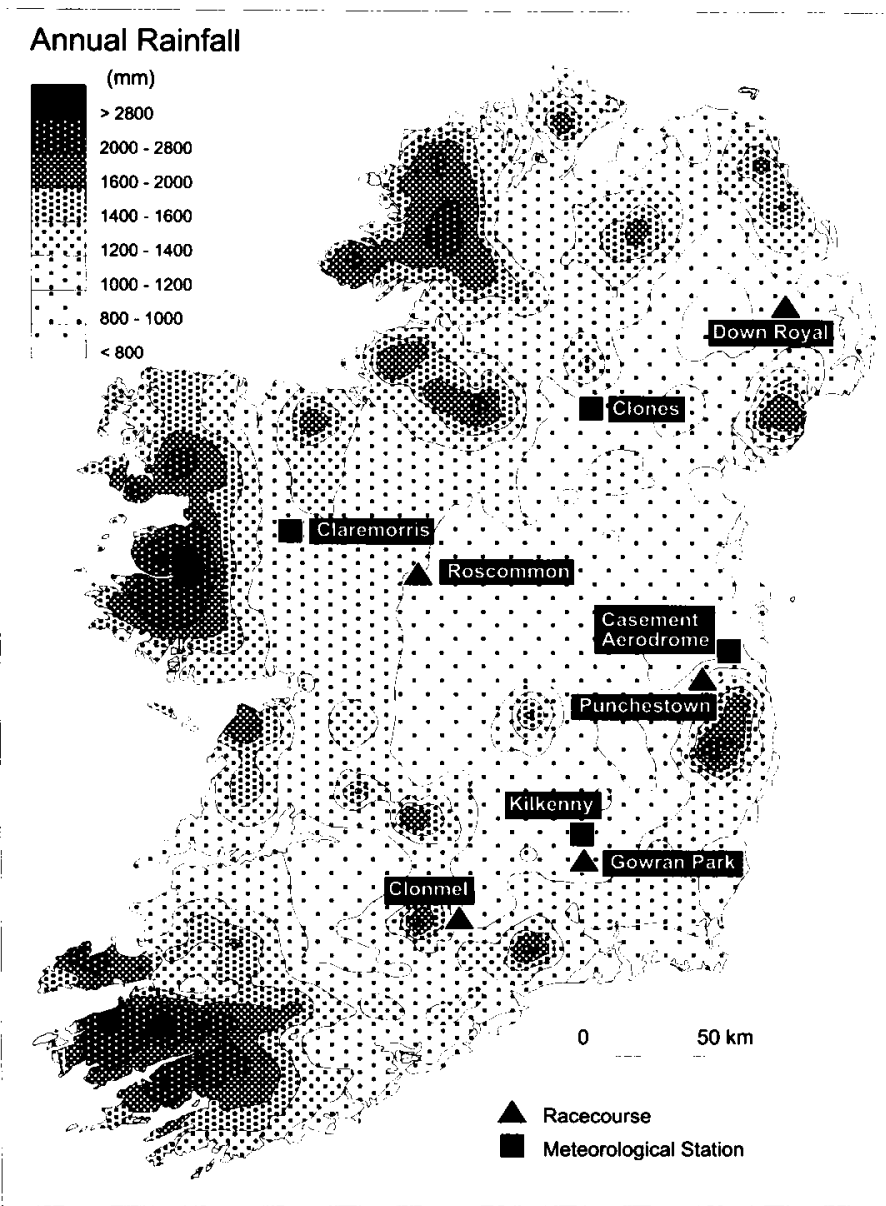

Fig. 1 Locations of racecourses and synoptic stations in relation to annual average rainfall (1961-90)

Sheep graze the track when racing ceases and help to maintain the grass cover at a low and even height.

\section{Gowran Park}

The Gowran Park track is located $15 \mathrm{~km}$ from Kilkenny and is about $2.5 \mathrm{~km}$ in length. An average of one meeting per month throughout the year limits its recovery time and mechanical measures are undertaken to maintain the course. The subsoil is clay-rich meaning that Gowran is a slow-draining track very vulnerable to compaction and waterlogging. After each meeting divots are replaced by machinery. This is a less meticulous form of maintenance than the human alternative and so the track is not as well repaired as manually repaired tracks. Under very dry conditions, the clay soils become very hard and, because of this, the track has an extensive watering system 150 computer-controlled sprinkler outlets give the clerk of the course the ability to soften ground to permit racing to take place when otherwise cancellation would have been necessary.

\section{Roscommon}

The most westerly course in the group, Roscommon, is slightly shorter than Gowran Park. About seven meetings are held annually from late spring to autumn. Unlike the other tracks, Roscommon is owned locally and great care is evident in its management. It is said to be the best maintained course in Ireland, despite being sited on a clay-rich subsoil. Unlike Gowran Park it tends not to suffer from com- 
paction and waterlogging because of the attention it receives. With no racing over the winter, it also has time to recover from any damage occurring during the summer season.

\section{Down Royal}

The Down Royal course is outside Lisburn in Northern Ireland and the undulating circuit measures $3.5 \mathrm{~km}$. One meeting per month takes place all year round. Light, sandy, subsoil provides excellent drainage, even in the wettest of weather and, accordingly, meetings are seldom abandoned.

\section{Clonmel}

Clonmel is in Co. Tipperary and also averages one meeting per month over the full year. The track is $2.5 \mathrm{~km}$ in length and constructed on subsoil with a high clay content. For many years major drainage problems were a feature of this course and a high percentage of winter meetings had to be abandoned. A subsurface drainage system installed in 1997 has improved matters considerably.

It may be hypothesised that, in the absence of effective course management, racecourses which are short in length, have a large number of winter meetings, and are situated on clayrich subsoil will be the most vulnerable to adverse weather conditions. Such courses will also be the most likely to have meetings abandoned due to adverse going in both summer and winter. The objective of this study is thus to examine a selection of Irish racecourses in order to ascertain whether knowledge of these relationships may be employed to derive a predictive model for the going at a particular course and which may have more general application for predicting the going at racecourses where meteorological data exist at nearby locations.

\section{Methodology}

Precipitation, temperature, wind speed and sunshine were considered to be the principal meteorological variables affecting the going, and records of these for the period 1980-97
Table 1 Numerical categories for different types of going

\begin{tabular}{cl}
\hline Category & Description of going \\
\hline 0 & Abandoned \\
1 & Heavy \\
2 & Soft-heavy \\
3 & Soft \\
4 & Yielding-soft \\
5 & Yielding \\
6 & Good-yielding \\
7 & Good \\
8 & Good-firm \\
9 & Firm \\
\hline
\end{tabular}

were obtained from Met Eireann. For each course, data were used from the nearest available synoptic weather station (Fig. 1). At such locations observations are made on a 24-hour basis by trained observers. Averages for the seven days prior to each race were calculated. The rationale for choosing a seven-day antecedent period was somewhat arbitrary. However, for the synoptic stations concerned, the annual average wet-day rainfall yield was just under $6 \mathrm{~mm}$, while the annual average potential evapotranspiration was just over $1.2 \mathrm{~mm}$. On this basis it was felt that rainfall (or the lack of it) recorded several days before the meeting would still be affecting soil conditions on the day, though obviously events nearer the day of the meeting would be more influential.

The going at each of the racecourses was obtained from the Irish Racing Calendar, a turf form book produced annually with an account of all the races that took place, the order in which the horses finished and the condition of the ground the meeting was run on. For the purposes of this study each type of going was classified according to Table 1. Approximately 200 races per course were examined over the period 1980-97 and a step-wise multiple regression analysis was employed to examine the relationship between the weather variables and the going over this period.

\section{Results and discussion}

A summary of the results of the multiple regression analysis is shown in Table 2. A multiple correlation coefficient, $r$, of between 0.56 and 0.78 indicates that the model is predicting the going fairly successfully on individual days. 
Table 2 Summary of multiple regression characteristics derived from analysis of going at five racecourses using standard meteorological variables from nearby synoptic stations

\begin{tabular}{lccccc}
\hline & Punchestown & Clonmel & Gowran Park & Down Royal & Roscommon \\
\hline Intercept & 3.3579 & 1.6494 & 3.1028 & 4.8981 & 6.0713 \\
Sunshine coefficient $(S)$ & 0.0068 & 0.0049 & 0.0021 & 0.0007 & 0.0010 \\
Rainfall coefficient $(R)$ & -0.0051 & -0.0049 & -0.0045 & -0.0047 & -0.0048 \\
Temperature coefficient $(T)$ & 0.0313 & 0.0434 & 0.0349 & 0.0295 & 0.0184 \\
Wind coefficient $(W)$ & -0.0170 & -0.0169 & -0.0193 & -0.0161 & -0.0175 \\
Regression step order & $S, R, T, W$ & $T, R, S, W$ & $T, R, W, S$ & $T, R, W, S$ & $T, R, S, W$ \\
Multiple $r$ & 0.7812 & 0.7727 & 0.7438 & 0.6618 & 0.5618 \\
Standard error & 1.6803 & 1.9377 & 1.9368 & 1.9617 & 2.0893 \\
No. of races & 196 & 203 & 206 & 200 & 139 \\
\hline
\end{tabular}

In the case of Punchestown, over $61 \%$ of the variance in the going has been captured by the model. The standard error is less than 2 (going classes) for four of the five courses which may be considered a very encouraging outcome given the subjective nature of the variable seeking to be emulated.

Sunshine is identified as the most important variable at Punchestown, while temperature and rainfall appear to be the key variables elsewhere. Of the five racecourses, Punchestown is the most free-draining course and this may explain its apparently reduced sensitivity to rainfall. Indeed, when the largest discrepancies for individual days between actual and predicted going are examined for this course, further confirmation of this hypothesis is obtained. For example, on 16 December 1981 the model predicted the ground should be heavy (1) when the actual going was declared as yielding (5). In this case the model predicted largely on the basis that $21.4 \mathrm{~mm}$ of rain was measured over the seven days prior to the race day, an amount which would have normally rendered the ground saturated at this time of year. However, closer inspection reveals that this rain fell on two days (days 4 and 5 of the week prior to the race day), with no rain and good drying before and after the rain event. Clearly the sandy/gravelly soil was able to absorb this rainfall in a manner in which a clay substratum would not. Similar issues arise when explaining the discrepancies that occur in the other course predictions, and these suggest that a soil texture parameter might usefully be included in any further development of the regression model. This might enable a more generic predictive equation to be derived that may be of even wider applicability to courses not included in this analysis.

One other aspect in which the model may underperform is in its inability to take into account conditions existing before the commencement of the week before the meeting. This can be significant especially if the week commences with waterlogged conditions on clay-rich subsoils. The model is weakest for Roscommon which is the most westerly of the racecourses studied and for which the annual rainfall (Claremorris) is greatest at $1140 \mathrm{~mm}$. Even a week of minimal rainfall in advance of a race meeting may be insufficient to enable drying out of the soil at a location such as this. At Irish inland locations, daily average potential evapotranspiration during the months November-January is only $0.06 \mathrm{~mm}_{\text {day }}{ }^{-1}$ and only three summer months produce potential daily evapotranspiration values in excess of $2 \mathrm{~mm}$ day $^{-1}$ (Keane 1986). Further complications for any predictive model obviously occur when precipitation is in the form of snow, or when abandonment takes place other than for reasons of waterlogging, e.g. fog or severe frost.

Figure 2 shows a sample of the predicted versus actual going for Punchestown during the 1990 s. For these plots the predicted values were rounded to the nearest integer, and predicted values in excess of 9 rounded down to 9 . Good agreement is apparent, generally giving cause for optimism that the technique may be capable of achieving the objectives outlined earlier. By comparison a poorer performance in predicting the going at Roscommon is apparent in Fig. 3.

The importance of being able to predict the going is reinforced further when projections of 


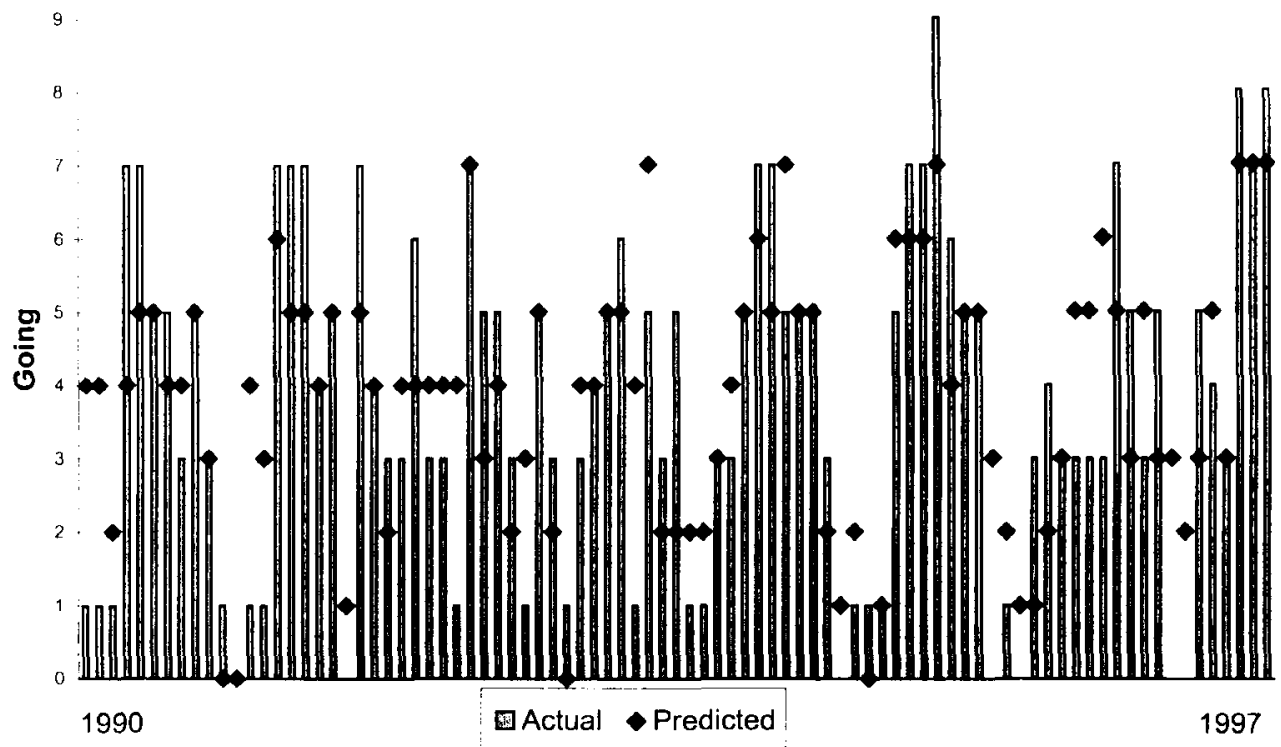

Fig. 2 Actual and predicted going at Punchestown 1990-97

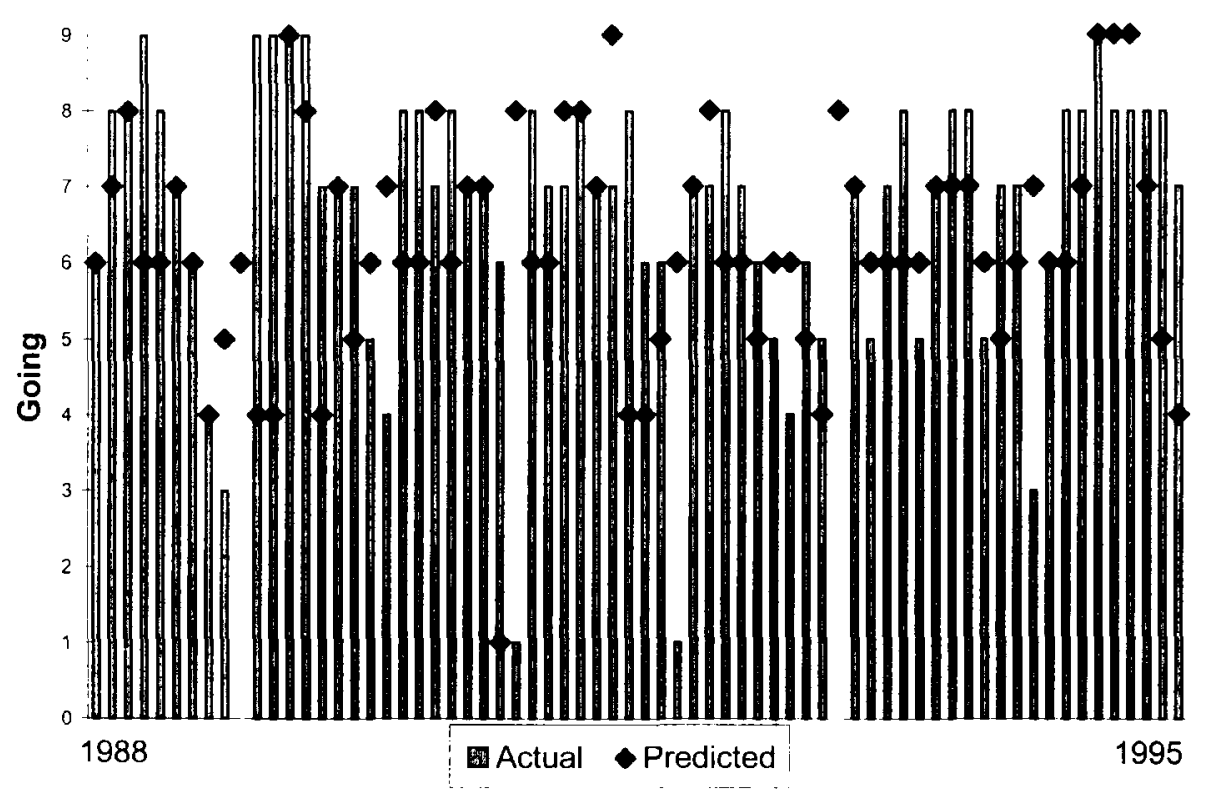

Fig. 3 Actual and predicted going at Roscommon 1988-95

climate change are considered. General estimates for potential evapotranspiration suggest that a $5 \%$ increase is likely for every $1 \mathrm{degC}$ of warming, though negative feedbacks may offset this somewhat (Arnell and Reynard 1993). What is more confidently predicted, however, is that increases in winter precipitation and decreases in summer precipitation of the order of $5 \%$ are likely by mid century (Hulme and Barrow 1997). Slightly greater changes are suggested for Ireland on the basis of known circulation-rainfall relationships (Sweeney 1997). If realised, such a situation would increase by a greater percentage the frequency of unfavour- 
able going conditions in both winter and summer, and for owners and trainers the ability to predict the going would thus become even more crucial.

\section{Conclusions}

Weather variables may be successfully employed to provide a predictive tool for estimation of the going at five Irish racecourses. Temperature, rainfall, sunshine and wind appear to explain approximately half the variance in this critical measure. Further fine tuning of the variables themselves and of the period chosen in advance of the meeting, the use of more proximate weather stations, and the possible incorporation of a soil texture variable would most probably enhance further the accuracy of the predictions concerned and offer a utility which trainers and racecourse managers, and even off-course betting agents, might find attractive.

\section{Acknowledgements}

The authors wish to acknowledge the assistance of the Irish Turf Club and Met Éireann in the provision of data for this paper.

\section{References}

Arnell, N. and Reynard, N. (1993) Impact of climate change on river flows in the UK. Institute of Hydrology Report to the UK Department of the Environment, Wallingford

Culleton, N. (1999) Grassland and grassland management. Module EV3915, Diploma in Equine Studies, University of Limerick

Hulme, M. and Barrow, E. (Eds) (1997) Climates of the British Isles. Routledge, London

Keane, T. (1986) Climate, weather and Irish agriculture. Joint Working Group on Applied Agricultural Meteorology (AGMET), Dublin

Morgan, R. P. (1985) Soil degradation and erosion as a result of agricultural practices. In: Richards, K., Arnett, R. and Ellis, S. (Eds) Geomorphology and soils. George Allen \& Unwin, London

Robinson, M. and Dean, T. (1993) Measurement of near surface soil water content using a capacitance probe. Hyrol. Process., 7, pp. 77-86

Russell, W. (1973) Soil conditions and plant growth, 10 th edition. Longman, London

Sweeney, J. (1997) Global warming scenarios and their implications for environmental management in Ireland. In: Sweeney, J. (Ed.) Global change and the Irish environment, Royal Irish Academy, Dublin, pp. 155-170

Correspondence to: Dr J. Sweeney, Department of Geography, National University of Ireland, Maynooth, Co. Kildare, Ireland.

\title{
Rainfall over Accra, 1901-90
}

\author{
E. Ofori-Sarpong and John Annor \\ Department of Geography and Resource Development, University of Ghana
}

Accra is the largest city and capital of Ghana. It is located in the south-east coastal plains of Ghana at $05^{\circ} 35^{\prime} \mathrm{N}, 00^{\circ} 60^{\prime} \mathrm{W}$. The south-east coastal plains are low-lying with a general altitude less than $152 \mathrm{~m}$ above sea-level, while several parts of Accra which are prone to flooding are below $60 \mathrm{~m}$. Rainfall is therefore one of the most important climatic factors to affect the peri-urban agriculture and socio-economic life of the city. Too much rain can result in severe flooding, as was witnessed on 4 July 1995, for example, when several parts of Accra recorded over $180 \mathrm{~mm}$ in a day. About 22 people lost their lives, and millions of US dollars' worth of properties were destroyed, including the city's entire communication network.

In this study we analyse rainfall data over 90 years. The analysis of such a long period of data will assist engineers, hydrologists, urban and transport planners, and agriculturists in the long-term planning of the city. The monthly and annual rainfall data used for the analysis were obtained from the Ghana Meteorological Services Department. 